\title{
Routing Protocol berbasis Cluster Segitiga
}

\author{
Nurhayati \\ Dosen Program Studi Teknik Informatika \\ Fakultas Sains dan Teknologi \\ Universitas Islam Negeri Syarif Hidayatullah Jakarta \\ e-mail: nurhayatibuslim@gmail.com
}

\begin{abstract}
Wireless sensor networks users are increasing drastically in communication and technology. They consist of small battery powered devices with limited energy resources. Once deployed, the small sensor nodes are usually inaccessible to the user, and thus replacement of the energy source is not feasible. However, the smaller of a device the better it is. The development of device should be user friendly. Hence, energy efficiency is a key design issue that needs to be enhanced in order to improve the life span of the network. In BCDCP, all sensors send data from $\mathrm{CH}$ (Cluster Head) and then to BS (Base Station). BCDCP works well in small-scale network but in large scale network it is not appropriated since it uses much energy for long distance wireless communication. We propose a routing protocol - Triangular Clustering Routing Protocol (TCRP) - to prolong network life time through the balanced energy consumption. RPTC selects cluster head of triangular shape. The sensor field is divided into energy level and in every level we choose one node as a gate node. This gate node collects data and sends it to the leader node. Finally the leader node sends the aggregated data to the BS. We show TCRP outperforms BCDCP with several experiments.
\end{abstract}

Key words: Wireless Sensor Network, Routing Protocol, Clustering

\section{PENDAHULUAN}

Kemajuan terbaru dalam komunikasi nirkabel dan elektronik telah memungkinkan pengembangan biaya rendah, daya rendah, sensor node berukuran kecil. Dalam WSN, sensor node dapat digunakan untuk mengumpulkan informasi yang berguna dari lapangan. Banyak routing protokol baru yang diusulkan untuk jaringan sensor nirkabel. Efisiensi energi adalah faktor yang paling penting untuk memperpanjang jaringan seumur hidup dan keseimbangan konsumsi energi. Meskipun dalam skala kecil jaringan, BCDCP bekerja dengan baik untuk rute data energi secara efisien; topologi jaringan mereka menghambat mereka ketika diterapkan untuk jaringan skala besar. Karena topologi klub di cluster adalah suatu skema rute satu-hop, tidak dialokasikan untuk komunikasi nirkabel jarak jauh. Selanjutnya, ketika ada banyak node, sensor node ke base station terdekat akan mati cepat, karena beban data yang dikirim pada base station.

Ini adalah kelemahan dari BCDCP, karena itu kami mengusulkan Clustering Routing Protokol berdasarkan metode seleksi Segitiga di Jaringan Wireless Sensor untuk menyeimbangkan konsumsi energi dan memperpanjang waktu hidup jaringan. Metode ini didasarkan pada konsentris dan BCDCP, tapi dengan menambahkan beberapa level dan membuat cluster node dalam bentuk segitiga untuk memperpanjang waktu hidup jaringan dan konsumsi keseimbangan energi. Sensor node di sebarkan secara random dalam jaringan dan jaringan dibagi ke dalam level yang kemudian dikelompokkan ke dalam sensor node atau kelompok dalam bentuk segitiga di setiap tingkat. Satu node dalam setiap bentuk segitiga dipilih sebagai kepala cluster dan kepala klaster mengirimkan data ke yang lain kepala cluster segitiga. Setiap Kepala Cluster Gerbang memilih salah satu Kepala Cluster untuk mengumpulkan data dari $\mathrm{CH}$ di setiap tingkat. Node dengan energi tinggi dan yang lebih dekat dengan base station yang dipilih sebagai pemimpin kepala cluster. Kepala Cluster Gerbang di setiap tingkatan mengirimkan data ke kepala cluster gerbang di tingkat lain dan lagi itu dikirim kepada pemimpin kepala cluster berikutnya dan akhirnya ke base station.

Struktur makalah ini adalah sebagai berikut: bagian kedua menjelaskan penelitian-penelitian terkait, yang ketiga menggambarkan pengelompokan routing protokol dalam jaringan segitiga sensor nirkabel, keempat menjelaskan simulasi dan analisis dan akhirnya kelima adalah kesimpulan.

\section{PENELITIAN YANG BERELASI}

Metode clustering pada LEACH adalah dibuat dengan mengelompokkan node-node ke dalam cluster dan kelompok, dimana kelompok tersebut terdiri dari kepala cluster dan anggota cluster. Informasi adalah menyatukan menjadi Kepala Cluster $(\mathrm{CH})$ sebelum dikirim ke base station. Informasi ini dibagi kedalam beberapa putaran; setiap putaran terdiri dari tahap set-up phase and steady set phase. Set up phase didefinisikan sebagai pengorganisasian clustercluster ketika steady set phase mendefinisikan proses di 
mana kepala cluster menerima data dari semua cluster dan mengirimkannya ke base station. Untuk menyeimbangkan beban energi, LEACH dimasukkan random rotasi dari posisi energi yang tinggi di kepala cluster di antara sensor-sensor. Tetapi metode di mana kepala klaster secara langsung mengirimkan data ke sink mengkonsumsi lebih banyak energi pada kepala cluster.

Pada BCDCP setiap node memiliki pengelompokan yang similar (serupa) seperti LEACH. Pertama, satu kepala cluster adalah dipilih secara acak untuk meneruskan data ke base station. Karena kepala cluster di setiap cluster akan mengirimkan data ke kepala cluster yang paling dekat dengannya didasarkan pada minimum spanning tree, ini membebani routing untuk ke base station (BS). Cluster Kepala mengirim data ke kepala cluster yang terpilih dan akhirnya $\mathrm{CH}$ mengirim data ke base station (BS). Jadi, BCDCP adalah memiliki kelemahan ketika ada sejumlah besar sensor node dan kepala cluster. Karena jumlah besar, node sensor membutuhkan lebih banyak energi untuk transmisi data intra dan antar cluster. Hal ini menciptakan ketidakseimbangan dalam konsumsi energi dan menurunkan umur hidup jaringan.

Kita dapat melihat bahwa BCDCP [6] adalah lebih efisien daripada LEACH dalam dua aspek, pertama dengan memperkenalkan Minimal Spanning Tree (MST)[2] untuk menghubungkan ke $\mathrm{CH}$ yang secara random memilih Leader untuk mengirim data ke sink. Kedua, BCDCP membuat penggunaan terbaik dari $\mathrm{BS}$ energi yang tinggi untuk memilih $\mathrm{CHs}$ dan bentuk cluster yang interaktif dengan mensplit algoritma. Jadi BCDCP mengurangi energi dissipasi jaringan jauh lebih dari LEACH, namun keduanya memiliki kelemahan dalam jaringan skala kecil. LEACH dan BCDCP bekerja dengan baik untuk energi efisien pada putaran data, namun topologi jaringan mereka menghambat mereka dalam jaringan skala besar. Karena topologi klub di cluster adalah suatu skema ruting satu-hop, tidak dialokasikan untuk komunikasi jarak jauh pada nirkabel.

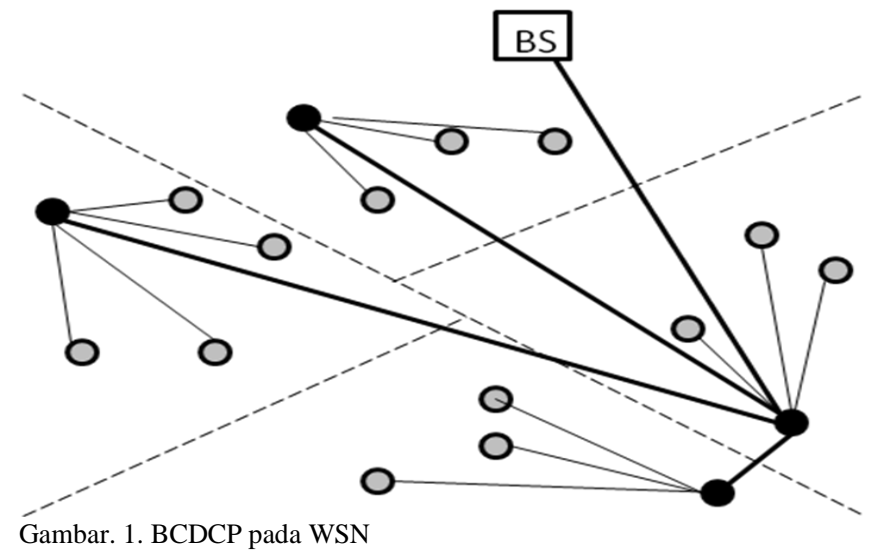

Jadi makalah ini mengusulkan Routing Protocol Cluster Segitiga (RPCT) pada Jaringan Sensor Nirkabel untuk daerah jaringan besar. Gagasan utama adalah: untuk intra-clustercluster dan antar transmisi data kami dibagi ke dalam level area jaringan. Setiap level memiliki satu cluster kepala gerbang yang berfungsi untuk menerima data dari kepala cluster setiap tingkat. Hasil simulasi menunjukkan seumur hidup jaringan dan keseimbangan konsumsi energi BCDCP dibandingkan dengan CTRP di area jaringan yang besar.

\section{TRIANGULAR CLUSTERING ROUTING PROTOCOL PADA WIRELESS SENSOR NETWORK}

Model untuk sistem routing protokol didasarkan pada asumsi sebagai berikut:

1. Base station terletak jauh dari bidang sensor. Sensor node dan base station menjadi statis setelah menyebarkan secara acak di area jaringan

2. Sensor adalah homogen dan memiliki kemampuan yang sama; setiap node diberikan sebuah pengenal yang unik (ID). 3. Sensor mampu beroperasi di node aktif atau mode tidur berdaya rendah.

4. Sensor dapat menggunakan kontrol daya untuk memvariasikan kekuatan daya transmisi sesuai dengan jarak penerima yang diinginkan

\section{A. Radio Model}

Model radio terdiri dari tiga bagian: pemancar, power amplifier dan penerima. Ada dua model propagasi: model ruang bebas dan dua model propagasi abu-abu [7]. Model ruang bebas (daya yang hilang $\mathrm{d}^{2}$ ) dan (dua penyebarkan abu-abu) yang multipath fading (daya yang hilang $\mathrm{d}^{4}$ ) model saluran yang digunakan tergantung pada jarak antara pemancar dan penerima. Dalam makalah ini penelitian energi yang dihabiskan untuk transmisi dari sebuah paket 1-bit dari pemancar ke penerima pada jarak d didefinisikan sebagai:

$$
\begin{aligned}
\operatorname{ET}_{\mathrm{x}}(1, \mathrm{~d})=1 \mathrm{E}_{\text {elec }}+1 \varepsilon \mathrm{d}_{\alpha} & =1 \mathrm{E}_{\text {elec }}+1 \varepsilon \mathrm{fsd}^{2}, \mathrm{~d}<\mathrm{d}_{0} \text { or } \\
& =1 \mathrm{E}_{\text {elec }}+1 \varepsilon \operatorname{tgd}^{4}, \mathrm{~d} \geq \mathrm{d}_{0}
\end{aligned}
$$

$E T_{x}$ is energy terdisipasi dalam pemancar dari node sumber dan energi elektronik $E_{\text {elec }}$ energi disipasi bit per untuk menjalankan sirkuit transceiver. Berikut energi amplifier, $\varepsilon \mathrm{fsd}^{2}$ or $\varepsilon \operatorname{tgd}^{4}$, tergantung pada jarak transmisi dan bit error rate yang diterima. Persilangan jarak $\mathrm{d}_{0}$ dapat di peroleh dari:

$$
\mathrm{d}_{0}=\sqrt{ }(\varepsilon \mathrm{fs} / \varepsilon \operatorname{tg})
$$

Energi yang dikeluarkan untuk menerima pesan adalah:

$$
\mathrm{ER}_{\mathrm{x}}(1)=\mathrm{lE}_{\mathrm{elec}}
$$

B. Routing Protocol Cluster Segitiga pada Wireless Sensor Network

Protokol routing ini memberikan kontribusi untuk menyeimbangkan konsumsi energi dan memperpanjang umur jaringan sensor node. Jadi untuk alasan ini kami mengusulkan Routing Protocol Cluster Segitiga untuk routing yang pendek. Metode bentuk segitiga, mirip dengan metode pohon biner mengurangi jumlah transmisi oleh setiap node karena setiap node tidak mengirimkan data langsung ke base station. Metode segitiga, mirip dengan pohon biner adalah sebuah struktur data pohon di mana setiap node 
memiliki paling banyak dua anak. Biasanya node pertama dikenal sebagai orangtua dan node anak disebut node node dan kanan kiri. Dalam teori, sebuah pohon biner dengan simpul tipe A didefinisikan sebagai induktif TA $=\mu \alpha .1+\mathrm{A} \times$ $\alpha \times \alpha$. Pohon biner biasanya digunakan untuk mengimplementasikan pencarian biner. Kami membuat routing dengan asumsi:

- Node disebarkan secara random di area jaringan dan tiap node menjadi statis setelah di sebarkan.

- Bidang jaringan dibagi ke dalam partisi level dan nodenode di group ke dalam cluster segitiga kecil pada tiap partisi level.

- Setiap tingkat memilih satu node sebagai pintu gerbang, sehingga setiap kepala cluster di setiap tingkat partisi mengirimkan data ke gerbang node yang selanjutnya dikirim ke base station.

- Rotasi kepala klaster membuat keseimbangan energi konsumsi.

- Jika energi dari kepala cluster yang mengering karena dekat dengan base station, kepala cluster lain dapat mengirim data langsung ke base station.

- Memiliki 3 fase: konstruksi awal atau pembentukan cluster, cluster konstruksi, cluster rekonstruksi segitiga

Fase awal atau pembentukan cluster: Bidang jaringan dibagi menjadi tingkat partisi yang sama. Setelah menyebarkan node secara acak dalam area jaringan, sensor menjadi statis. Ini terdiri dari semua informasi tentang ID, energi residual node dan jarak dari node ke base station. Node memilih kepala cluster dan anggota cluster. Pemilihan kepala cluster adalah didasarkan pada energi dan jarak antara node ke base station. Node dengan energi tertinggi dan dekat dengan base station akan dipilih sebagai kepala cluster di setiap tingkat. Dan kepala cluster dengan energi tertinggi serta paling dekat dengan base station di setiap tingkatan akan dipilih sebagai gerbang kepala cluster.

Konstruksi dari cluster: simpul tersebut dikelompokkan ke dalam kelompok segitiga kecil mirip dengan pembentukan pohon. Satu node dipilih sebagai kepala cluster dan dua node sebagai anggota cluster. Setiap tingkat memiliki gerbang kepala cluster. Node dengan energi tertinggi dan paling dekat dengan base station dipilih sebagai gerbang kepala cluster. Setiap node mengirim data ke kepala cluster dalam cluster yang segitiga kecil dan kemudian kepala cluster yang mengirimkan data ke kepala cluster yang berdekatan dengan energi yang lebih tinggi. Selanjutnya kepala cluster mengirim data ke gerbang, Dan gerbang kepala cluster mengirimkannya ke pemimpin kepala cluster, kepala cluster akhirnya pemimpin kirim ke base station. Setelah pengiriman data ke base station energi dari node atau kepala cluster yang menurun Oleh karena itu, setiap node dan kepala cluster dapat berotasi untuk menyeimbangkan konsumsi energi.

Fase rekonstruksi segitiga: Fase ini adalah untuk pemeliharaan. Setelah pengiriman data ke base station jika energi gerbang kepala klaster menjadi lebih rendah dari energi di node tetangga, dapat memilih lain kepala cluster sebagai pemimpin untuk mengirimkan data ke base station. Kepala cluster dapat berotasi untuk menyeimbangkan konsumsi energi dan memperpanjang umur jaringan.
Algoritma cluster segitiga routing protokol dijelaskan dan ditunjukkan dengan gambar di bawah ini:

1. Pada awalnya kita dikerahkan sensor secara acak di daerah jaringan;

2. Sensor node menjadi statis setelah menyebarkan;

3. Bagi area jaringan ke tingkat partisi yang sama;

4. Setiap sensor node mengirimkan informasi (ID, level, Sisa energi, Jarak) ke BS;

5. BS menghitung dan menyimpan semua informasi dalam tabel informasi (ID, Level, Energi Residual, jarak);

6. Setiap node memilih simpul tetangga terdekat untuk membuat cluster segitiga di setiap tingkatan;

7. Diperiksa untuk node dengan informasi yang sesuai dengan informasi pada tabel(ID, Level, RE, d) dalam BS;

8. Setiap node mengirim data ke Kepala Cluster $(\mathrm{CH})$, di setiap tingkat, dan algoritma memilih satu $\mathrm{CH}$ sebagai Gerbang Kepala Cluster untuk mengumpulkan data;

9. $\mathrm{CH}$ gerbang di setiap tingkat mengirim agregat data untuk $\mathrm{CH}$ Pemimpin dan akhirnya $\mathrm{CH}$ Pemimpin mengirimkannya ke base station
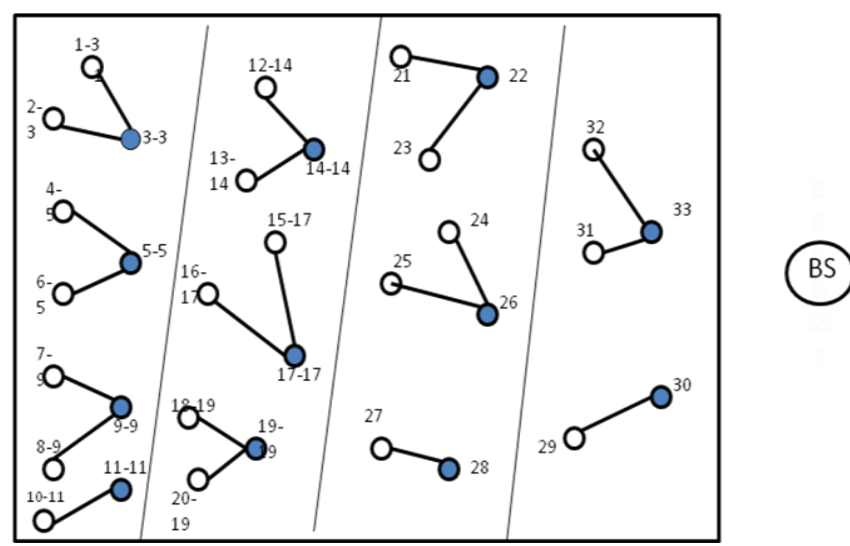

Gambar. 2. Cluster segitiga di wireless sensor network

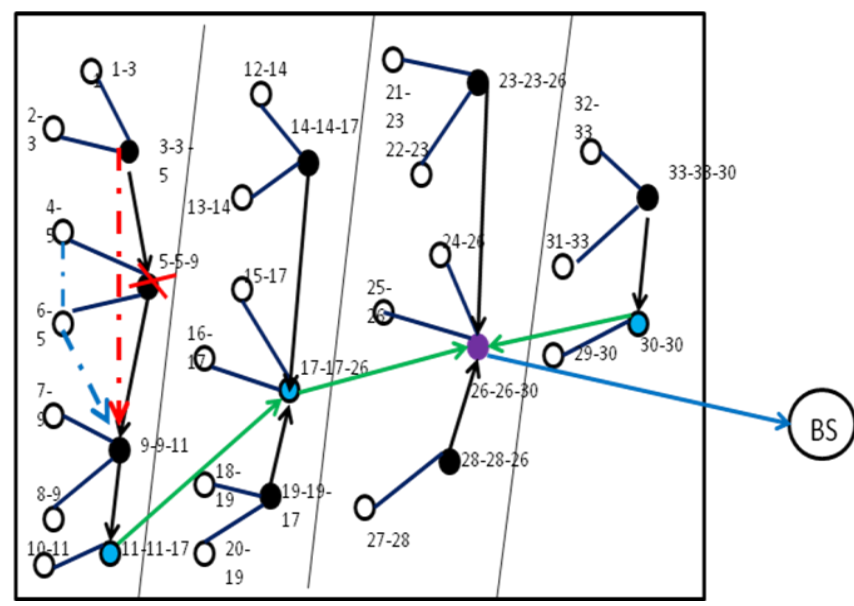

Gambar. 3. Routing di cluster segitiga

\section{ANALYSIS AND SIMULATION RESULTS}

Dalam bagian ini kami mengevaluasi kinerja Routing Protocol Cluster Segitiga (CTRP) melalui simulasi dan dibandingkan dengan BCDCP. Pertama kita mempelajari karakteristik dari clustering dan algoritma routing segitiga, maka kita menyelidiki pengaturan parameter dan efisiensi energi CTRP dalam hal waktu hidup jaringan, karena 
makalah ini berfokus pada menyeimbangkan energi konsumsi dan efisiensi waktu hidup Jaringan

Dalam makalah ini waktu hidup jaringan ditentukan oleh jumlah putaran yang dibuat oleh node sampai node pertama mati. Simpul pertama mati berarti node pertama kehabisan energi dalam jaringan. Satu putaran didefinisikan operasi dari awal pembentukan cluster sampai akhirnya base station menerima semua data dari pimpinan kepala klaster.

Parameter yang digunakan diasumsikan dalam simulasi kami diringkas dalam tabel 1 .

$<$ Tabel 1> Parameter-parameter Simulasi

\begin{tabular}{ll}
\hline Parameter & Nilai \\
\hline Network field & $(0,0)-(100,100) \mathrm{m}$ \\
Base station location & $(150,50) \mathrm{m}$ \\
$\mathrm{N}$ & 100 \\
Initial energy & $1 \mathrm{~J}$ \\
$\mathrm{E}_{\text {elec }}$ & $50 \mathrm{~nJ} / \mathrm{bit}$ \\
$\varepsilon \mathrm{fs}$ & $10 \mathrm{pJ} / \mathrm{bit} / \mathrm{m} 2$ \\
$\varepsilon \mathrm{mp}$ & $0.0013 \mathrm{pJ} / \mathrm{bit} / \mathrm{m} 4$ \\
$\mathrm{~d}_{\mathrm{o}}$ & $87 \mathrm{~m}$ \\
EDA & $5 \mathrm{~nJ} / \mathrm{bit} / \mathrm{signal}$ \\
Data packet size & $4000 \mathrm{bits}$ \\
\end{tabular}

Hasil simulasi seperti berikut ini:

a. Perbandingan TCRP's dengan rata-rata energy yang menghilang dengan BCDCP.

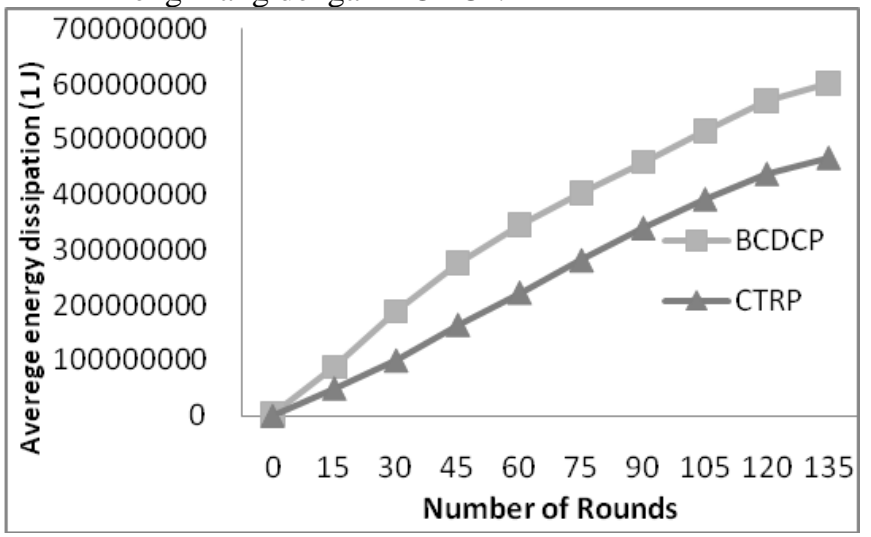

Gambar 4. Perbandingan TCRP's dengan rata-rata energy dissipation dengan BCDCP.

Gambar 4 menunjukkan rata-rata energi yang digunakan atas jumlah putaran ketika kita digunakan CTRP dan BCDCP sebagai protokol yang ada. CTRP mengurangi konsumsi energi yang signifikan atas BCDCP, karena bentuk metode segitiga untuk memilih kepala cluster dan gerbang kepala cluster di setiap tingkat dalam CTRP lebih efisien dalam mengkonsumsi energi lebih sedikit untuk baik intra dan cluster transmisi data antar di setiap tingkat. Pengurangan $30 \%$ dalam rata-rata energi yang dipakai energi dapat menunjukan BCDCP melebihi CTRP itu berarti CTRP mengkonsumsi energi sekitar 30\% kurang dari BCDCP. Selanjutnya kita bisa lihat di grafik kurva BCDCP yang lebih tinggi dari CTRP dan disipasi bervariasi antara putaran. Jadi CTRP memiliki kinerja lebih baik daripada BCDCP dalam hal efisiensi energi dan dapat memperpanjang masa pakai jaringan dari sensor node.

b. Masa hidup dari sensor nodes sampai node pertama kali mati

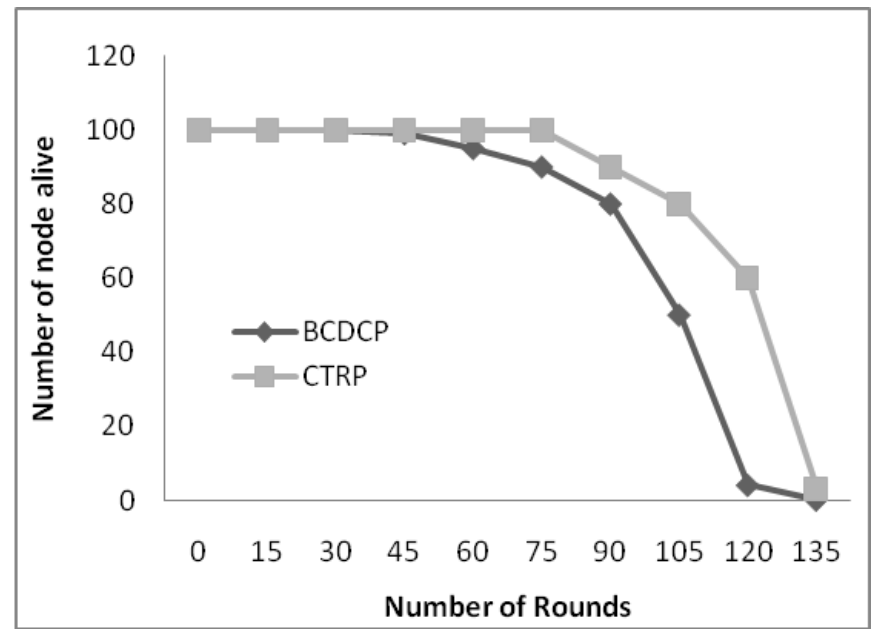

Gambar 5. Perbandingan masa hidup system pada RPCT dengan BCDCP

Dalam gambar 5. Jumlah masa hidup node adalah seumur hidup (jumlah node sensor hidup sampai node pertama mati) untuk CTRP lebih BCDCP terlihat jelas. Dalam kasus waktu kehidupan BCDCP dimulai berkurang di putaran 60 dan dalam hal CTRP itu dimulai berkurang pada lebih dari 90 putaran. Kami menghitung bahwa dalam kasus BCDCP node mati $36 \%$ lebih cepat dari CTRP. Itu berarti rata-rata jumlah node sensor tinggal di CTRP adalah $36 \%$ lebih tinggi dari BCDCP. Jadi CTRP memperpanjang waktu hidup jaringan dan keseimbangan konsumsi energi daripada BCDCP. Juga grafik CTRP lebih licin dari BCDCP.

\section{CONCLUSION}

Dalam tulisan ini kami mengusulkan Clustering Segitiga Routing Protocol (CTRP), yang memanfaatkan energi tinggi pada base station untuk melakukan tugas energi yang paling efisien. Dengan menggunakan base station sensor node terbebas dari menjalankan tugas energi komputasi intensif seperti setup cluster, pemilihan kepala klaster, routing formasi. Node sensor dibuat menjadi simpul cluster dan dibagi ke dalam tingkatan yang berbeda. Setiap tingkat memiliki satu gerbang kepala cluster untuk menerima semua data dari kepala klaster yang kemudian dikirim ke tingkat lain dan akhirnya ke base station. Segitiga ini Clustering Routing Protocol rotasi dan pemilihan kepala cluster adalah berdasarkan energi sisa yang lebih tinggi dalam sensor node dan node jarak ke stasiun pangkalan, node dengan energi yang lebih tinggi dan dekat dengan base station akan dipilih sebagai kepala cluster dalam setiap putaran. Kami berasumsi bahwa base station memiliki semua informasi dari node sensor, dan energi sisa dan jarak dari node telah didefinisikan. Semua hasil yang ditunjukkan dalam simulasi untuk jaringan seumur hidup dan keseimbangan konsumsi energi BCDCP itu miskin bila dibandingkan dengan CTRP dalam jaringan area yang luas. Hasil untuk CTRP lebih baik dari hasil 
BCDCP. Ini membuktikan bahwa CTRP dapat memperpanjang jaringan seumur hidup dan konsumsi keseimbangan energi.

\section{REFERENSI}

[1] Guangyan Huang, Xiawei Li, Jing He, "Dynamic Minimal Spanning Tree Routing Protocol for Large Wireless Sensor Networks", ICIEA, 2006.

[2] H. Shen, "Finding the k Most Vital Edges with Respect to Minimum Spanning Tree," in Proceedings of IEEE Nat'1. Aerospace and Elect. Conf., vol. 1, pp.255-262, 1997.

[3] Jung-Eun Lee, kieechon Kim, "Diamond-Shaped Routing Method for Reliable Data Transmision in Wireless Sensor Networks", International Symposium on Parallel Distributed Processing with applications.(ISPA), pp. 799-801, 2008 IEEE.

[4] Stephanie Lindsey, Cauligi S. Raghavendra, "PowerEfficient GAthering in Sensor Information Systems", IEEE, 2002, Volume: 3, On page(s): 3-1125- 3-1130 vol.3.

[5] Sung-Min Jung, Young-Ju Han, Tai-Myoung Chung,"The Concentric Clustering Scheme for Efficient Energy consumption in the PEGASIS", International Conference on Advanced Communication Technology (ICACT), Vol.1, pp.260-265, Feb.2007.

[6] S. D. Muruganathan, D. C. F Ma., R. I. Bhasin, and A. O. Fapojuwo, "A Centralized Energy-Efficient Routing Protocol for Wireless Sensor Networks," IEEE Communications Magazine, vol.43, pp. 8-13, 2005.

[7] W. Heinzelman, A. Chandrakasan and H. Balakrishnan, An application-specific protocol architecture for wireless micro sensor networks, IEEE Transactions on Wireless Communications 1(4) (2005) 660-670. 